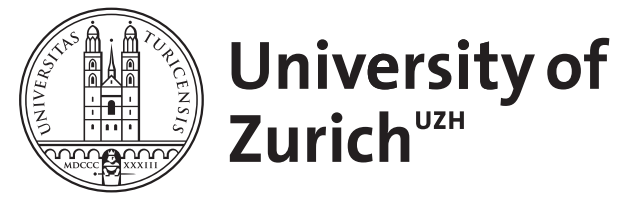

Zurich Open Repository and Archive

University of Zurich

University Library

Strickhofstrasse 39

CH-8057 Zurich

www.zora.uzh.ch

Year: 2012

\title{
Non-human knowledge and non-human agency
}

Glock, Hans Johann

Posted at the Zurich Open Repository and Archive, University of Zurich

ZORA URL: https://doi.org/10.5167/uzh-72925

Book Section

Published Version

Originally published at:

Glock, Hans Johann (2012). Non-human knowledge and non-human agency. In: Tolksdorf, Stefan. Conceptions of knowledge. New York: de Gruyter, 521-551. 


\title{
Non-Human Knowledge and Non-Human Agency
}

\author{
Hans-Johann Glock
}

My project is to compare human and non-human animals (henceforth simply animals) with respect to knowledge. More generally, I shall consider the applicability to animals of epistemic concepts like knowledge, belief, perception, etc. These epistemic concepts are intimately connected to what one might call practical concepts- action, agency, intention, reason for acting, etc. For one thing, the most basic function of epistemic concepts is to explain and justify action; for another, the notion of a reason plays a central role in both the epistemic and the practical sphere. Accordingly, my exploration of animal knowledge will be intertwined with a discussion of animal agency. Of course, both epistemic and practical concepts are also connected to mental notions in general, of which they form important sub-classes.

Traditionally, knowledge or cognition is counted among the 'higher' mental faculties, as opposed to conative or emotive ones. In recent years, however, there has also been a tendency in some quarters to dissociate the term 'cognition' from any mental connotations. Ironically, this trend derives from the so-called cognitive revolution. Although they abandoned many of the methodological restrictions of behaviourism, cognitive scientists continued to look askance at mental phenomena like consciousness, which appear to defy scientific investigation because of being irreducibly private. This qualm is based on an untenable, Cartesian conception of the mind, however ${ }^{1}$, and I shall assume that epistemic or cognitive phenomena form part of mental phenomena.

Now, there are two opposing stances on animal minds. Differentialists maintain that there are crucial qualitative differences separating us from animals; assimilationists insist that the differences are merely quantitative and gradual. The most important variant of differentialism is lingualism. It denies on a priori grounds that animals without a language can have mental capacities at all, or at least 'higher' mental capacities like those required for knowledge and rational agency. This raises the question of whether there are conceptual connections between the posses-

1 See e.g. Glock (2001b). 
sion of language on the one hand, and the possession of mental capacities in general and cognitive capacities in particular on the other. Because I am interested in these connections, I shall focus on animals without language, leaving aside the hotly contested question of whether some animals are capable of acquiring rudimentary symbolic skills. It is not my ambition, however, to tackle all the lingualist objections against crediting animals with mental powers. I have repudiated many of them elsewhere ${ }^{2}$, and shall focus here on those connected to knowledge and other epistemic concepts.

I approach these topics from the perspective of recent revisionionist ideas in epistemology and theory of action. In my view, these ideas undermine certain forms of differentialism-cum-lingualism, since they remove apparent hurdles to accepting animal knowledge and agency. ${ }^{3}$ As regards knowledge, if knowledge is not true justified belief, then animals cannot be excluded on the grounds that they lack the rational faculties that might be prerequisites for being justified. As regards agency, if reasons for action are not subjective mental states but objective features of the subject's environment, then animals may be capable of acting for a reason without possessing demanding types of self-consciousness, viz. awareness of their own mental states. At the same time, the revisionist ideas throw up new challenges to assimilationism, some of which I hope to meet. This paper focuses on epistemic concepts. I shall briefly discuss agency at the beginning, however. For epistemic and practical concepts need to be seen in conjunction. And the most important weakness of differentialism is that the basic connections between the two apply to animals no less than humans.

2 Glock (2000) and (2010).

3 Another area in which the comparison can yield fruits concerns the role of agency for cognitive states. With much fanfare, Fodor has trumpeted the view that cognitive states like knowledge and belief are independent of and indeed prior to action and conative states like intending or desiring. The animalhuman comparison instead favours the loosely-speaking pragmatist view that we should understand mental states in the context of human and non-human practice. At the same time, one ought to resist a tendency among some recent pragmatists, notably Brandom, namely of drawing a distinction between human practice and animal behaviour that is so sharp and categorical as to rules out the possibility of intermediate stages and hence the possibility of providing a genetic (evolutionary) explanation of the emergence of evolved human knowledge and action. 


\section{Methodological Prolegomena}

Knowledge and agency have been proposed as prerogatives of humans, the former in conjunction with thought, the latter under a variety of headings, which include not just action but also praxis and volition. Indeed, some authors give the impression that their accounts of knowledge, action or rational action are motivated at least partly by a desire to ensure that they are beyond the of for animals. ${ }^{4}$ In some philosophers one also suspects the opposite tendency, namely to explain various notions of agency, in particular, in such a way that they are attainable for animals, because of moral implications. Neither strategy commends itself. If the questions of whether animals can know or act are to have any point, these notions must not be construed ab initio so as to imply either a negative or a positive answer. Rather, they should be construed in ways that are plausible or fruitful on independent grounds.

In this context it is not just legitimate but imperative to start out from the ordinary use of 'know' and 'act', as well as their cognates and equivalents in other languages. In pursuing any question of the form 'What is X?' we shall inevitably rely on a preliminary notion of $\mathrm{X}$, an idea of what constitutes the topic of our investigation. In our case we presuppose a preliminary understanding of knowledge and agency. This is not a fully-articulated conception, which would have to emerge from the subsequent debates in epistemology or theory of ac-

4 Thus Alvarez maintains that the only motivating reasons are facts (e.g. Alvarez 2010, 3, ch. 4). She grants that we can answer the question 'Why are you $V$ ing?' by citing a goal. Yet she resists the suggestion that goals can be motivating reasons on the following grounds: 'If goals were reasons, it would follow that any animal that acts in pursuit of a goal would also act for a reason. But whereas it is fairly uncontroversial that a dog who digs in order to find a bone acts in pursuit of a goal, it is much more controversial to say that the dog acts for a reason: that what motivates the dog to dig is a reason, namely that digging is a means to find the bone, and that the dog acts guided by that reason'. (Alvarez 2010, 98). But the passage up to the colon simply assumes that reasons should not be the sort of things for which animals can act. Yet it is perfectly unexceptional to say that the reason why the dog digs is that it is looking for a bone. And the passage following the colon does not provide an independent argument against such statements. Even if it is problematic to say that the dog is motivated by the fact that digging is a means to find the bone, this gloss of 'the dog has a reason/is guided by a reason' is forced on us only on the very assumption that the argument purports to justify, namely that goals cannot be reasons, since only facts can be reasons. There is nothing amiss with 'The dog has a reason for digging, namely its goal of finding a bone'. 
tion, but an initial idea of what those debates are about. Such a pretheoretical understanding is embodied in the established uses of the relevant epistemic and practical terms.

One might object that for philosophical and scientific purposes we need to graduate from ordinary use towards a more specialized one based on more exacting scrutiny of the phenomena. But this is not an objection to my procedure. First, unless the relation between the novel and the established ways of using the pertinent expressions (between the new and the old concepts) is properly understood, the philosophical problems associated with these expressions will merely be swept under the carpet. ${ }^{5}$ Secondly, all neologisms and conceptual modifications, those of science included, need to be explained. By pain of regress, this can ultimately be done only in terms of ordinary expressions which are already understood. Finally, the term 'ordinary use' is ambiguous. It may refer either to the standard use of a term as opposed to its irregular use in whatever area it is employed, or to its everyday as opposed to its specialist or technical use. ${ }^{6}$ My starting point is the standard use. Both the explanation of epistemic and practical concepts and claims about their applicability to animals should in the first instance be measured not against philosophical theories, but against the uses of the relevant terms in established and legitimate forms of discourse. In our case, the latter will include everyday parlance; yet they will also include specialized disciplines from the behavioural sciences, the social sciences and jurisprudence.

Now, we freely apply a wide range of epistemic and practical concepts to higher animals and non-linguistic humans. This is not just an indispensible part of everyday life, but also central to disciplines like comparative psychology, cognitive ethology and developmental psychology. This fact provides at least a prima facie reason against explaining these concepts in ways that preclude such applications. A lingualist has the following options for responding to this fact.

First, he can adopt an error theory, maintaining that ordinary folk and scientists are simply mistaken in crediting animals with epistemic and practical properties. Now, it is possible to regard the ascriptions of some epistemic and practical concepts to some species of animals as

\footnotetext{
5 Strawson (1963).

6 Ryle (1953), 301-304.
} 
empirically false. ${ }^{7}$ But it is not easy to see how one could regard the ascription of all types of epistemic and practical concepts to all species of animals as empirically false.

In any event, most lingualists adopt a second line. They often regard such attributions not as false, but as suffering from a more basic defect, namely that of being meaningless, nonsensical or based on a categorymistake. ${ }^{8}$ If the concept of thought is such that it precludes application to non-linguistic creatures, nothing could count as evidence that some animals have thoughts. Ascribing thoughts to animals would then make no more sense than ascribing a colour to a number. Yet it remains a mystery how we could be so fundamentally confused about such basic concepts, not just when language is idling, as in philosophical reflection, but also when it is fruitfully employed, as in everyday discourse and progressing empirical sciences.

These days, the harsh charge of nonsense has given way to a third response. Even though some thought ascriptions to animals are neither empirically false nor straightforwardly conceptually incoherent, the story goes, they cannot be taken literally, but must be regarded as figurative, metaphorical or secondary. We are dealing with a possibly useful but ultimately incorrect façon de parler. This stance is illustrated by Davidson's reaction to a well-known tale from Norman Malcolm.

Suppose our dog is chasing the neighbor's cat. The latter runs full tilt toward the oak tree, but suddenly swerves at the last moment and disappears up a nearby maple. The dog doesn't see this maneuver and on arriving at the oak tree he rears up on his hind feet, paws at the trunk as if trying to scale it, and barks excitedly into the branches above. We who observe this whole episode from a window say, "He thinks that the cat went up that oak tree". ${ }^{9}$

Malcolm claims that we would be right to say this, and Davidson acknowledges that it is prima facie plausible. Nevertheless, he insists that 'strictly speaking' Malcolm's dog cannot believe anything, because he does not possess a language..$^{10}$ An immediate objection to Davidson is this: animals must be capable of having thoughts because we have no better way of explaining and predicting their behavior than by attribut-

7 This is the case, for example, when ethologists like Seyfarth and Cheney (1996), 340-343 use observations to deny that vervet monkeys have a "theory of mind", that is, beliefs about the beliefs of conspecifics.

8 E.g. Stoecker (2009), 268; cf. Fisher (1996), 4-8.

9 Malcolm (1972-73), 13.

10 Davidson (2001), 96-100. 
ing thoughts to them. ${ }^{11}$ Indeed, there may not even be a feasible alternative. In that case, such attributions would even satisfy a well-known methodological principle of comparative psychology. According to 'Morgan's canon', we should only attribute higher mental capacities to a creature if this is the only explanation of its behavioural capacities. ${ }^{12}$

A fourth and last ditch attempt grants this point, while insisting that some claims that are strictly speaking false are nonetheless indispensible. ${ }^{13}$ But this strategy requires a compelling explanation of how falsehoods can be indispensible not just for practical purposes, but also for perfectly respectable scientific disciplines like cognitive ethology. Furthermore, it not only needs to specify what it is about our extant concepts that precludes their literal application to animals, but also to explain why competent speakers are so blissfully ignorant of this inapplicability.

If these four responses indeed fail, one is entitled to hold it against an analysis of certain practical or epistemic concepts if it precludes their application to animals. ${ }^{14}$ Of course, there may be good reasons for modify-

11 See, e.g. Bennett (1976), \$\$7-8; Fodor (1975), ch. 1.

12 See Morgan (1894), $53 \mathrm{ff}$.

13 Stoecker (2009), 256, 268.

14 Thus Stoecker proposes that 'actions ... are just those of our doings that are due to our ability to align whatever we do to the call of reason, materialized in the call of the social practice' (Stoecker 2009, 267). He rightly infers from this premise that animals cannot act. But surely that conclusion simply counts against the premise. It goes to show that the proposed analysis is extensionally inadequate, and for a variety of reasons. It precludes not just inanimate objects, animals and fictional creatures like Davidson's swampman (see Glock 2003, $262 \mathrm{f}$.), but also human beings who have not participated in a linguistic social practice-such as feral children. The mere fact that Kaspar Hauser grew up outside of a linguistic community would not lead us to deny that he acted when he fled from captivity; and we have no reason to adopt such a restrictive stance simply because it follows from popular theories advanced by some externalists and communitarians. Finally, Stoecker's argument in defence of his premise is laudable in refusing to treat reasons as subjective mental states. Yet it is faulty in several respects. Let us grant, for the sake of argument, that 'reasons basically are arguments', and that in a reason explanation 'we say that the agent has acted because a particular argument spoke for her acting as she did'. Stoecker next tries to avoid reference to the agent's belief that something indeed speaks for her action by adding the assumption that 'I am wont to do what is arguably the best'. It is unclear how this move can avoid the objection that in error cases reference to the agent's belief is mandatory. Worse still, Stoecker maintains that the only way of explaining why someone is wont to do what is arguably the best is that he has been 'raised in a social communicative practice' (Stoecker 2009, 266). But this is a non-sequitur, since Stoecker does nothing 
ing our established epistemic and practical concepts. But this does nothing to salvage the lingualist case. For one thing, it provides no grounds whatever for answering questions like 'Can animals possess knowledge?' and 'Can animals act?' in the negative. For those questions are phrased in the extant, non-modified concepts. For another, assuming the indispensability of epistemic and practical notions that can be applied to animals, such conceptual reform has little to recommend it.

Rather than dismissing our established ways of describing and explaining animal behaviour as false, confused, metaphorical, attenuated, etc., one ought to consider the following option. In their established uses, our epistemic and practical terms have more or less demanding senses. In the less demanding ones they simply do apply to animals period, whereas in the more demanding ones they may not. ${ }^{15}$ And at least prima facie, it is more plausible to regard the simple senses as basic rather than secondary or degenerate.

to rule out alternative explanations. Finally, intelligent animals are just as wont to do what is arguably the best in the situations facing them as talkative yet thick humans in situations facing them. Even if all of these points could be waived, however, the argument would at best lead to the conclusion that animals cannot act for a reason. There are other bona fide types of action, notably actions that are subject to teleological explanations without being amenable to rational explanations (see Glock 2009, 239-244 and Alvarez 2010, 191-196).

15 My position here has points of overlap with Ernst's discussion of knowledge (2002), which I read only after finishing the first draft of this paper. He does not discuss the question of whether animals can possess knowledge. And instead of distinguishing between more or less demanding senses of ,know' he distinguishes between a sense in which we ascribe the term from the perspective of someone already in the know, and a sense in which we ascribe it from the perspective of somone who does not and seeks a reliable source of information. But the former sense is less demanding, in that it requires no more than true belief. And Ernst's discussion is grist to my mill in that from the perspective of someone in the know who either needs to decide whether to provide information or to explain behaviour, we have no qualms about distinguishing animals with from those without knowledge. If the dog has already seen the bone I placed in the bowl for its consumption, I don't need to point it out to him. And if Malcolm's dog does not know that the cat went up the maple, that explains why it is barking up the wrong tree. 


\section{Animal agency}

Practical notions like act, action, agency, intentional action, action for a reason illustrate this point. They are notoriously complex and diverse. The only sensible strategy is to distinguish between different senses of the relevant terms, and to consider their applicability to animals. In what follows, I can only provide an exceedingly brief sketch. ${ }^{16}$

The most general question in this area runs: Can animals act? That general question must be answered in the affirmative by those revisionists who accept non-intentional agency, including agency by inanimate objects. If

(1) The wind knocked over the vase

and

(2) The bleach ruined the linen

report agency in this general sense, then so do

(3) The cat knocked over the vase

and

(4) The dog ruined the linen.

At a grammatical level, we apply an active/passive distinction to many kinds of inanimate objects. When it comes to living things, that distinction takes on a new foundation in reality. For here we can distinguish between what an organism does and what happens to it by reference to the organism's needs. Thus plants fulfil their needs by growing roots, orienting their leaves, emitting chemical substances to deter predators, etc. By contrast, they are subjected to various things that are neutral to or detrimental to these needs.

When it comes to animals, we encounter not just needs but also wants (goals and purposes). And here the aforementioned distinction applies with a vengeance. An animal can be thrown over a fence or trip accidentally, or it can jump over a fence or fall to the floor obeying an order. In the former case, it is not just needs that remain unfulfilled, certain wants desires of the animal are frustrated or thwarted. And such frustration, just like the fulfilment of the wants, is manifest in the animal's behaviour.

It is points like this that underlie a prominent psychological definition, according to which action is simply behaviour directed towards a

16 See Glock (2009). 
goal. ${ }^{17}$ According to a venerable philosophical tradition, by contrast, human agency goes beyond this level. It is behaviour that has been caused by a special kind of mental event, a volition. Now, it is far from obvious that one cannot credit animals with volitions in the sense of decisions. After all, there are animals that are not just intelligent, but whose bodily demeanour, facial expressions and activities resemble some of ours, notably the great apes. In these, at least, trained observers can easily detect states of indecision. For instance, one can note how characteristic activities are interrupted by obstacles and problems, how these interruptions are followed by inactivity and characteristic displacement activities and gestures (including the proverbial scratching of heads), and how at the end of the behavioural cycle problem solving activity ensues. Nevertheless, the voluntarist tradition in action theory is less accommodating to animal agency than the current orthodoxy. ${ }^{18}$ According to that orthodoxy, the most fundamental feature of human agency is that it is intentional. And that in turn is taken to mean that it is subject to intentional explanations-explanations that refer to the agent's reasons-her beliefs, desires, intentions, goals, purposes, etc.

Animal behaviour is subject to intentional explanations, precisely because animals are capable of acting purposively or intentionally, in pursuit of their own goals. The question that has been hotly disputed recently is whether they are capable of acting for a reason. According to orthodoxy reasons are subjective mental states. This implies that acting for a reason requires the capacity to reflect on one's own mental states. That is a high hurdle. For revisionists, by contrast, reasons are objective conditions - facts, states of affairs, etc. In so far as animals have cognitive capacities, they have access to such objective conditions. And in so far as the deliverances of these capacities guide their behaviour, they are capable of acting for reasons. But revisionists of a differentialist inclination balk at that suggestion. For instance, it has been suggested that animals might be said to act for a reason, a.k.a. goal, without having a reason, since they cannot reflect on these reasons. Two assimilationist responses suggest themselves: one is to question the idea that one can have reasons only if one can reflect on these reasons; the other is to argue that animals can reason or reflect on reasons.

17 See White (1979), 1.

18 Thus Stoecker (2009), 259 notes that it is more plausible to say that a cat intends to stalk a bird than to say that it has decided to do so. 
This is not the place to resolve these issues. For us the crucial point is that the applicability of intentional explanations to animal behaviour implies the same connection between epistemic capacities-in particular perception-knowledge, belief and action that one also finds in humans.

\section{Intentional verbs}

As is evident from intentional explanations, our epistemic and our practical concepts are intimately linked to intentional verbs. These verbs occur mainly in three sentential forms:

$\begin{array}{llll}\text { I } & \text { A } & V \mathrm{~s} \text { (knows/thinks/believes/expects, etc.) } & \text { that } p \\ \text { II } & \mathrm{A} & V \mathrm{~s} \text { (intends/plans/means, etc.) } & \text { to } \Phi \\ \text { III } & \mathrm{A} & V \mathrm{~s} \text { (loves/desires/thinks about, etc.) } & X\end{array}$

According to an orthodoxy going back to Russell, the verbs that can replace ' $V$ ' denote different types of intentional attitudes, 'A' the subject of these attitudes, and the substitution instances of 'that $p$ ', 'to $\Phi$ ' or ' $X$ ' their contents. Statements of all three forms can display a hallmark of intentionality, namely that nothing in reality needs to correspond to the (grammatical) direct object: one can believe something which is not the case, intend to do something which never happens, and love someone who does not exist. ${ }^{19}$ Prima facie, (I) expresses a propositional attitude, (II) an action-oriented attitude, (III) an object-oriented attitude. Nonetheless it is customary to subsume all forms of intentionality under the heading 'propositional attitude'. This is no coincidence. There is a pervasive tendency to regard (I) as basic and to disregard other forms of intentionality, and this by itself gives succour to lingualists. For the term 'proposition' carries strong linguistic connotations. In some contexts, it is downright equivalent to 'sentence in the indicative', in others it signifies something expressed by a sentence and (perhaps) designated by a thatclause or more generally a noun-clause (see below).

However, I know of no compelling reduction of action- and objectoriented attitudes to proposition-oriented attitudes. ${ }^{20}$ In the absence of

19 Some intentional verbs may not display this feature, in particular in type III contexts. For instance, it is a moot question whether one can regret things one has never done or know a person that does not exist.

20 McDowell (1996) may be right to reject 'non-conceptual content' if he means to insist that every object we can identify perceptually can somehow be described conceptually. It does not follow, however, that there is a list of propositions 
such a reduction, it is sheer dogmatism to insist that admiring Nelson Mandela, intending to climb a tree or craving M\&Ms are in the final analysis attitudes towards propositions. Of course, the reasons people have for admiring Mandela or intending to climb a tree can be expressed through that-clauses. But so can the reasons people have for kicking a ball, and no one would conclude that kicking a ball is therefore anything other than a relation to an object. This removes an obstacle to crediting animals with intentional states. For it would be foolhardy to deny that chimpanzees can intend to climb trees or crave M\&Ms, unless one is in thrall to the prejudice that all intentional states must an fond be attitudes towards propositions. ${ }^{21}$

which captures precisely and completely what I currently perceive-my visual field. Tugendhat (1982), ch. 6 regards the reduction of all intentional states to propositional attitudes as a distinctive trait of analytic philosophy. He defends this stance on the grounds that even those intentional states which are ostensibly directed towards objects, for example loving, pitying or admiring someone, imply propositional attitudes, attitudes the expression of which involves a that-clause. Even though Dorothea Brooke does not exist, I can admire her only if I believe that she exists. And even if I picture Dorothea Brooke to myself as a fictional character, I picture her as existing. But this argument is unconvincing. To be sure, to imagine an apple is not to imagine an apple as non-existing, but neither is it the same as to imagine that there is an apple, which is what $\mathrm{Tu}$ gendhat needs to establish. Moreover, it is far from obvious that when I imagine Dorothea Brooke, I imagine her as existing rather than as non-existing (provided that either of these options makes sense in the first place). Kenny (1963), chs. $\mathrm{V}$, XI steers a different course to a proximate destination. He maintains that sentences where 'I want' is followed by a direct object (rather than by an infinitive), as in 'I want an $X$ ' can often be expanded into sentences of the form 'I want to $\Phi$ an $X^{\prime}$ : I want an apple - I want to eat an apple, etc. Furthermore, in reports of what he calls 'affective attitudes' the grammatical object of the attitude takes a different form depending on the verb: either a 'that' clause, or an infinitive (I hope that $p$, I want to $\Phi$; I prefer to $\Phi$, etc.). Nonetheless, he maintains, they could all be expressed using the construction 'A volits that $p$ ', since he thinks of these affective attitudes as taking an attitude to a state of affairs. Although this would leave type (III) intentionality unaffected, it would mean that type (II) cases could be reduced to type (I), and hence to something propositional. But it is far from obvious that intending to do something is tantamount to wanting a certain state of affairs to come about. It certainly doesn't amount simply to voliting that the results of the action come about. And even if statements of the form 'A wants to $\Phi$ ' could be paraphrased by statements of the form 'A volits that $p$ ', it would not follow that the propositional construction is more basic. For the possibility of paraphrase cuts both ways, and the infinitive construction is much more readily understood than the propositional one.

21 Glock (2001); Alvarez (2010), $66 \mathrm{f}$. 
Let us nevertheless focus on intentional verbs of type (I), since here the lingualist worry - the 'proposition problem'-remains acute. Consider a belief ascription such as:

(5) Carl thinks that the cat went up that oak tree

On the one hand, there is the intentional verb ('believes'), which informs us that Carl believes, rather than, for example, knows or fears that the cat went up the oak tree. On the other hand, there is a noun-clause ('that the cat went up that oak tree'), which informs us of what it is that Carl believes, the content of his belief, and is therefore known as the content-clause. Switching to the material mode, there is the kind of intentional state on the one hand, the kind of content on the other. These two parameters are in turn connected to a well-known equivocation in nouns like 'belief, 'hope', 'desire', etc. 'A's belief can refer either to what $A$ believes, namely that the sun is out, or to what $A$ has, namely the belief that the sun is out. What A has, the belief, can be erroneous, sensible, or tentative. But what A believes-e. g. that the sun is out-i. e. the content of her belief, cannot. ${ }^{22}$

The two parameters raise two distinct questions. One is which intentional states can be ascribed-what intentional verbs can be applied to animals; another question is which contents can be ascribed to themwhich that-clauses, singular terms, infinitives or gerunds can follow these intentional verbs. ${ }^{23}$ Concerning the second question, Wittgenstein famously maintained that a dog can believe that its master is at the door, but not that its master will return the day after tomorrow. Concerning the first question, he suggested that dogs are incapable of hope, because that particular concept is applied on the basis of behavioural manifesta-

22 White (1972), $81 \mathrm{ff}$.

23 Stoecker (2009), $263 \mathrm{f}$. maintains that in reason explanations intentional attitudes play second fiddle to the contents. 'Except for the content, it does not matter much, how we specify the type of attitude'. But the difference between believing and knowing does play an enormous role, as we shall see. And so does the difference between $V$-ing because one wants to and $V$-ing because one is obliged to. Finally, there are not just 'pro attitudes'-in Davidson's terminology-but also con attitudes. I can desire, etc., $V$-ing, yet I can also hate, resent, deplore, etc. $V$-ing. It is interesting to note that with respect to negative conative verbs the continuous form comes more natural than the infinitival. While $A$ can be said to hate to $V$, this is less natural than to hate $V$-ing, and resent to $V$, deplore to $V$ etc. may be ungrammatical. It would be interesting to speculate whether there is a conceptual difference underlying this grammatical one. 
tions that are part of a 'complex form of life', that of linguistic humans. ${ }^{24}$ At a more general level, one might grant that animals can believe or perceive that $p$, yet deny that they can think or judge that $p$, since these are exercises of rational faculties. The next section is devoted to such a general issue, namely the applicability to animals of 'know' and 'believe'.

\section{Knowledge and Belief}

Few contemporary differentialists would deny that some animals possess knowledge how, in Ryle's phrase. Intelligent animals know how to do certain things, not just because they are genetically pre-programmed or have been behaviouristically conditioned, but also because they can learn how to do them off their own bats, whether by trial and error or even through foresight and planning. The moot point is whether animals are capable of what Ryle called knowledge that. ${ }^{25}$ It is obvious, however, that the knowledge he had in mind is not tied to that particular grammatical construction. To know who, where, when or whether also constitutes what is sometimes known as propositional knowledgea label that is highly misleading, as we shall see. Accordingly, if a dog knows whether its master is at the door, it also knows that its master is (not) at the door, and mutatis mutandis for knowing who is at the door. If a chimpanzee knows where to find stones suitable for nutcracking, it also knows that such stones are to be found beneath yonder tree. If a scrub jay knows when it has cached a supply of worms, it also knows that the caching occurred so long ago that the worms are no longer edible. And since the antecedents are commonsensical or strongly supported by empirical evidence, why should it be problematic to ascribe propositional knowledge to animals?

The problems, I submit, are largely the product of contestable philosophical ideas about such knowledge. For proponents of orthodox accounts, belief is a necessary but not sufficient condition of knowledge.

24 Wittgenstein (1967), 174.

25 That animals possess knowledge how rules out combining a differentialist denial of knowledge that with the currently popular view that all cases of knowledge how can be reduced to knowledge that. An interesting issue remains, however. In the human case knowing how to $\Phi$ can be distinguished from the ability to $\Phi$. An old hunter may know how to skin a rabbit while no longer being able to do so. But can this distinction be drawn in the case of animals? Not by reference to an old chimpanzee telling offspring how to crack nuts with a stone 
By the same token, the capacity for belief is merely a necessary condition of the capacity for knowledge. This obviously holds for the tripartite conception of knowledge as true justified belief. On such an account, even if animals can believe that $p$, they could only know that $p$ if they were also justified in that belief. And if this in turn requires that they are capable of justifying that belief ${ }^{26}$, knowledge is unattainable for non-linguistic creatures.

The tripartite conception never recovered from the counterexamples devised in Gettier's article 'Is justified true belief knowledge?'. ${ }^{27}$ Yet the idea that knowledge is a type of belief soldiered on, even among many opponents of the tripartite concept. ${ }^{28}$ Given this assumption, knowledge is belief plus something (justification, proper warrant, suitable causal connection, etc.), and hence more demanding. The orthodoxy treats knowing as an 'elite suburb of believing'. ${ }^{29}$ Following Wittgenstein, Ryle and White, however, some epistemologists have questioned the idea that knowledge is a species of belief. Instead, the revisionist story goes, it is a kind of ability. Thus Hyman has argued that to know that $p$ just is to be able to believe or do something for the reason that $p .^{30}$

But isn't this from the frying pan into the fire for assimilationists, not to mention their pets? For how can animals believe or do something for a reason, without rational faculties? As indicated in section II, however, it is far from obvious that a creature can only believe or do something for a reason if it is capable of stating those reasons or to reflect on them. Furthermore, if animals are capable of acting for a reason only in an attenuated sense, the same might hold for their capacity to know. Finally, if my methodological prolegomena are correct, then to the extent to which an account of knowledge rules out cognitively controlled and fruitful applications of epistemic concepts to animals, it also stands in need of revision, e. g. in need of being restricted to humans.

To add force to this last point, the next section argues that crediting animals with certain forms of knowledge is not merely legitimate but inevitable, not just but especially if knowledge is a kind of ability. In the following section I shall tackle a radical attack on orthodox accounts

26 A substantial if, see Glock (2009).

27 Gettier (1963).

28 E.g. Williamson (2000).

29 Ryle (1974), 5.

30 Hyman (1999). 
of knowledge. It questions an assumption that the orthodoxy shares with its more moderate critics, namely that a creature that is incapable of having beliefs must also be incapable of having knowledge. According to Marcus, animals can know things, yet they cannot believe things. It will transpire that this claim is untenable. Furthermore, it is partly based on a failure to question an orthodoxy in the philosophy of mind, namely the aforementioned assumption that intentional verbs signify 'propositional attitudes', relations between a subject and a proposition.

\section{Knowledgeable Brutes!}

There are countless examples for everyday attributions of knowledge to higher animals. If Malcolm's dog had noticed the cat's change of course and behaved accordingly, we would have no qualms about

(6) The dog knows that the cat is in the maple tree

Cognitive ethology has added a wealth of more astonishing cases. ${ }^{31}$ In many of them, there are legitimate disputes over how precisely to describe the animals' achievements. ${ }^{32}$ But these concern the question of what precisely the animals know and how they came by that knowledge. That they do have knowledge of certain facts is not in dispute.

There are good reasons for this consensus. First, both everyday and scientific observations demonstrate that animals have cognitive capacities, capacities to gain information. Indeed, some findings clearly indi-

31 See Bekoff/Jamieson (1996); Tomasello/Call (1997); Hurley/Nudds (2006). Here is a selection. Chimpanzees know whether there is food in a container, and not just through direct perception. They can pick the baited among two containers, when they hear that another container shaken by the experimenter doesn't emit a characteristic noise. Chimpanzees know whether an experimenter will cooperate or not. They will point to the baited of two containers when dealing with an experimenter that has been cooperative in the past, to the unbaited, when dealing with an experimenter that has in the past appropriated the indicated container. Scrub jays know not just where they have hidden food, but also whether they have been observed doing so. What is more, they know whether food hidden is still edible.

32 Is some kind of disjunctive inference in play the first case? Do the chimpanzees in the second case know what the experimenters intend to do, or only how they will react? Is the astonishingly intelligent behaviour of the scrub jays a manifestation of episodic memory, etc.? 
cate that these capacities are not confined to perception. Still, perception by itself suffices to show that animals are capable of gaining knowledge.

It would be absurd to deny that animals are capable of perception. They can learn about their environment by using their sensory organs. However, perceiving that $p$ implies knowing that $p$, if 'perceiving' is used as a factive verb, as it commonly is in both the human and the animal case. Accordingly, since animals can perceive that $p$, they are capable of knowing that $p$. Lingualists will contest the idea that seeing is knowing. But on what grounds? The most attractive option for them is to argue as follows. Animal perception is confined to perceiving $X$, i.e. to perceiving objects or events; it does not include perceiving that $p .^{33}$ This would mean that they are capable only of type III intentionality, not of type I intentionality. But this response is implausible. The perceptually informed reactions of higher animals to their environment can only be explained by a capacity to perceive that $p$. For instance, the dog sees a bone on the table, but it has been trained not to grab anything on the table and hence simply looks on, panting. Yet as soon as the bone is placed on the floor, the dog grabs it. This sequence of events is not explained by the dog simply seeing a bone, a table or the floor, but only by its seeing first that the bone is on the table and then that it is on the floor. One might maintain that the problem vanishes if spatial relations like $x$ being on $y$ are among the objects that the dog can perceive. However, simply perceiving three distinct objects-bone, table, $x$ being on $\gamma$-does not explain the dog's behaviour. Such an explanation is only in the offing if the dog can also perceive that the bone stands in the relation of being on to the table at one moment, to the floor at the next. And in that case we are back with perceiving that $p$. Nor can the lingualist defuse the argument by insisting that the dog simply perceives (sees, smells, etc.) the bone on the table or the bone on the floor. For either the apposition 'on the table' is used restrictively to identify what bone it sees, in which case the dog's seeing the bone on the table goes no further towards explaining its behaviour with respect to the table than its simply seeing a bone. Or it is shorthand for 'being on the table'. But perceiving the bone being on the table is perceiving that the bone is on the table by another name. Consequently there is no way around the admission that animals can perceive that something is the case, just as we can. ${ }^{34}$

33 Thus Dretske, e.g. Dretske (2004) distinguishes between 'seeing things' and 'seeing facts', maintaining that only the latter is conceptual.

34 Glock (2010). 
Furthermore, animals display a kind of behavioural response to what they have learnt through perception which is analogous to the human case- a response appropriate to the circumstances. For instance, vervet monkeys react in a characteristic fashion to different predators, and they signal these different predators through distinctive alarm calls. ${ }^{35}$ Furthermore, a vervet monkey that has fled from a snake onto a tree knows that it is safe. And we know that it knows because it is no longer agitated and no longer signals danger, instead observing the snake in a detached, impassive fashion. ${ }^{36}$

Finallly, in higher animals we can detect the same nexus between perception, knowledge and action that is crucial to the application of epistemic and practical concepts to humans, especially according to revisionist accounts. Consider the following ingenious example by Marcus, involving his cat Opie. ${ }^{37}$

(7) Opie tries to paw the pantry door open in order to retrieve the treats.

(8) Opie paws the pantry door open because he is retrieving the treats.

(9) Opie paws the pantry door open because he is trying to retrieve the treats.

(10) Opie paws the pantry door open because the treats are in the pantry.

If Opie fails to paw the pantry door open, (8) - (10) are out of order, just as they would be in the human case. If Opie succeeds at pawing the pantry door open, yet the pantry contains no treats, (9) is in order, while (8) and (10) are not. For these explanations require knowledge of facts. The analogy with human knowledge extends to Gettier style cases, at least if these are dealt with along revisionist lines. Suppose Marcus has moved the treats to the shelf above the pantry. The treats then happen to fall behind the shelf and back into the pantry. Opie, not having observed the switch and suffering from a stuffy nose, is unaware of these developments. In that case we might say

(11) Opie paws the door open because the treats are usually in the pantry

or

35 Seyfarth/Cheney (1996).

36 See Rundle (1997), 87.

37 Marcus (2011), ch. 3. 
(12) Opie paws the door open because he expects the treats to be in the pantry.

But Opie doesn't paw the door open because the treats are in the pantry full stop, as in (10). For '[h]is expectation's being met was merely fortuitous'.

\section{Incredulous Brutes?}

Marcus rightly concludes that animals are capable of knowledge. Turning received wisdom on its head, however, he demurs at granting that they are capable of belief. His line of reasoning can be reconstructed to run roughly as follows.

$\left(\mathrm{P}_{1}\right)$ Knowledge is a relation between a subject and a fact

$\left(\mathrm{P}_{2}\right)$ Animals can be related (in an appropriate fashion) to facts

$\left(\mathrm{C}_{1}\right)$ Animals can know things

$\left(\mathrm{P}_{3}\right)$ Belief is a relation between a subject and a proposition

$\left(\mathrm{P}_{4}\right)$ Animals cannot be related (in an appropriate fashion) to propositions

$\left(\mathrm{C}_{2}\right)$ Animals cannot believe things

Although $\mathrm{P}_{1}$ and $\mathrm{P}_{2}$ require careful elaboration, we should accept $\mathrm{C}_{1}$, for the reasons rehearsed in the last section. A rationale for accepting $\mathrm{P}_{4}$ will emerge in section VIII. Right now I turn to the argument in favour of $\mathrm{P}_{3}$, which Marcus derives from Vendler. According to both, 'that' clauses are systematically ambiguous between a fact-interpretation, and a proposition-interpretation. 'that $p$ ' in ' $A$ believes that $p$ ' always refers to a proposition, whereas 'that $p$ ' in ' $A$ knows that $p$ ' always refers to a fact. This thesis rightly presupposes that facts and propositions are not to be equated, their logical isomorphism notwithstanding. And Vendler brings to light genuine differences between the roles of thatclauses in belief- and know-strings, respectively. Consider

(13) John believes that grass is green.

(14) I know what John believes.

(15) I believe what John believes.

Vendler's thesis is that ' $A$ knows __' takes facts as objects, whereas ' $\underline{A}$ believes__' takes propositions as objects. Accordingly, 'what John believes' in (14) cannot refer to the object of John's belief - the proposition that grass is green-since the latter is not a fact. And sure enough, (14) does not mean that I know that grass is green. Rather it means that I 
know that John believes grass is green, which is the fact expressed by (13) as a whole. (14) is similar to

(16) I know what he lost.

in which 'what he lost' is a new sentence-nominalization-a 'wh-nominalization' —of 'that he lost a watch'. By contrast, 'what John believes' in (15) refers back to the proposition on display in (13), viz., that grass is green. In this respect, (13) is similar to

(17) I found what he lost.

where 'what he lost' ultimately derives from a relative clause. (15) is tantamount to

(15') I believe that which he believes [namely, that grass is green].

The cases that cause trouble for Vendler's thesis are those employing two verbs, such as

(18) John believes what Mary knows

These mixed cases seem to show that belief and knowledge can have the same object. Vendler dismisses (18) as ungrammatical. Yet that dismissal seems theory-driven. In any event, no competent speaker would balk at a slight modification:

(18') John merely believes that $p$ while Mary knows $i^{38}$

Marcus for his part suggests that mixed cases trade on an ambiguity concerning that-p, which is made to do double-duty, to refer to a proposition in the first conjunct, a fact in the second. He assimilates (18') to cases of syllepsis such as

(19) Ron was still off his rocker and his medications.

Yet ordinary speakers would not regard (19) as a syllepsis, a potentially comical crossing of categories. The addition of 'merely' to (18) does not serve to cross a categorial divide-between propositions and facts. It simply indicates that the sentence settles the 'intra-categorial' question of whether what Mary is stated to know is that John believes that $p$ or rather that $\mathrm{p}$.

Finally, the diagnosis of syllepsis is even less plausible for mixed cases involving the same subject, such as

38 Marcus uses the example 'I merely believe what John (truly) knows', which leaves one with a puzzle about how he could be in a position to state that John knows that $p$ yet credit himself with the mere belief that $p$. 
(20) She now knows what she used merely to believe, namely that exercise is good for you.

Consequently, there is no case for holding that 'that'-clauses are categorially ambiguous in the way maintained by Vendler. ${ }^{39}$

Ironically, it is Vendler's claim that what we know is always a fact that runs up against categorial distinctions of standard English.

(21) $A$ knows that $p$

does not imply

(22) $A$ knows the fact that $p(\star)$

Rather, it implies

(23) It is a fact that $p$

and arguably-if $A$ possesses the concept of a fact-

(24) $A$ knows that it is a fact that $p$.

We shall see below that matters stand even worse for the claim that what we believe are always propositions.

\section{Retreat from Knowledge}

It transpires that Vendler's logico-grammatical considerations do not rule out ascriptions of beliefs to animals. What is more, there is an obvious problem with the idea that animals are knowers but cannot be believers, namely the problem of accounting for cases of error or mistake. Animals possess cognitive, and in particular perceptual, faculties which, properly exercised, yield knowledge about the environment. As Malcolm's example illustrates, however, they can also exercise these cognitive capacities in inadequate or insufficient manner. In that case, they do not possess knowledge, even though their behaviour is still guided by these faculties. ${ }^{40}$ Attribution of belief is in order, because in the case of animals no less than in the case of humans, there is the possibility of epistemic failure as well as success.

Small wonder, then, that even a differentialist like Rundle writes: 'Certainly, we do no violence to language in speaking of knowledge

39 See also White (1982), 45-54; Dolby (2007), ch. 1.1.2.

40 Davidson has famously argued that a creature cannot have a belief without being mistaken, and that this in turn requires possessing the concept of a mistake. The first claim is correct, the second mistaken. See Glock (2000). 
[in the case of animals], and, while it is not the most suitable term, "think" has, ..., an intelligible role in those cases where we are obliged to retreat from "know". After all, the move from knowledge to thought or belief can hardly be a move to a state which is more problematic $p s y$ chologically, as it were, given that it is made solely on the strength of the failure of a purely external condition'. ${ }^{41}$

The assimilationist needs to clear two obstacles at this stage. First, isn't the idea that in the case of epistemic failure we still have a case of belief a lapse back into the orthodox account of knowledge as belief plus something? The answer is: No! For we must distinguish between the proper analysis of knowledge and the question of whether the capacity for knowledge can be attributed without the capacity for belief. When $A$ knows that $p$, it is not a matter of A believing that $\mathrm{p}$ plus it being the case that $p$ plus something else. Nonetheless, only a creature that can (merely) believe that $p$ can also know that $p$, since only such a creature has cognitive capacities that play a role in explaining its behaviour. Indeed, when it comes to explaining behaviour, we do not distinguish between an explanation by reference to knowledge and an explanation by reference to mere belief. One and the same behaviour can be made intelligible by A knowing that $\mathrm{p}$ and by A merely believing that $\mathrm{p}$. That Sarah called out the ambulance is rendered intelligible by her believing that she has gone into labour, whether or not she is right.

The second obstacle is to account for animal belief in view of the assumption that belief is a relation between a subject and a proposition. Even Marcus describes the idea that we commit an error in attributing beliefs to animals through statements like (5) as 'charmless'. He thinks that our hands are forced, however, on pain of accepting that animals grasp propositions.

41 Rundle (1997), 89 f. To be sure, Rundle also insists that our ascriptions of belief and thought to animals are not a matter of knowledge. 'The dog believes that there is a squirrel in the tree'-'I am prepared to go along with that way of speaking'. But his reason is that there is no internal process of thought which the subject can manifest. It cannot be said that 'something takes place in the creatures head' which might be reportable by a sentence (Rundle 1997, 90, 105). But this is an unduly mentalistic conception of thinking, at odds with the insights of Ryle and oblivious to the array of thoughts that can be displayed in non-linguistic behaviour. 


\section{Propositional Attitudes' and Animal Intentionality}

The assumption that stands in the way of animal belief is $\mathrm{P}_{3}$, namely that belief is a relation between a subject and a proposition. That assumption is part and parcel of the orthodox picture of intentional states as relations between subjects and propositions (a picture that Vendler and Marcus reject for the case of knowledge yet accept for the case of belief). That picture rules out ascriptions of beliefs to animals quite irrespectively of Vendler's logico-grammatical considerations. According to orthodoxy, what a subject believes (the content of $A$ 's belief) is a proposition or thought, a complex object of which concepts are the components; thus the thought that dogs bark is a complex object of which the concepts DOG and BARK are parts. By these lights, if $A$ believes that $p$, then she stands in relations of grasping and accepting to an entity, a proposition, of which concepts are components. Thus orthodoxy presents a relational account of intentional states and a building-block model of propositions.

As mentioned above, the term 'proposition' is closely related to 'sentence', to the ears of philosophers, linguists and laypeople alike. It also suggests a claim or statement that is being proposed or advanced for consideration. An attitude towards a proposition therefore seems to require an understanding of something proposed, claimed or stated. Furthermore, on most accounts, propositions and concepts are not just linguistic but also abstract. Yet animals cannot stand in the appropriate cognitive/semantic relationship to such entities. ${ }^{42}$ Finally, on the orthodox view even straightforward propositional contents such as the one attributed in (5) include concepts like that of a cat or of a tree. But there are difficulties in supposing that animals could grasp and hence entertain these concepts.

One way of defusing the proposition problem is associated with Fodor. According to him propositions and concepts are particulars in the heads of individuals - notably sentences or words of a language of thought-rather than abstract entities. And such particulars occur in the brains of animals no less than in those of humans. Even creatures that do not speak a public language partake of the language of thought - provided their behaviour is explicable by reference to intentional states. As I have argued elsewhere, however, that position is untenable. Propositions and concepts cannot be particulars, since they can

42 See Glock (2010), 19; Alvarez (2010), 67; Marcus (2011). 
be shared between subjects. They are not signs, but what signs express. And the idea of a language of thought falls foul of the fact that a linguistic symbol is something that is used in a potentially conscious way by a subject. The neural processes Fodor has in mind may charitably be interpreted as causal enablers of thought, yet they cannot be symbols of a language. ${ }^{43}$

\section{Nonconceptual Content?!}

A more promising response to the proposition problem invokes the idea of 'nonconceptual content'. ${ }^{44}$ This response accepts that intentional verbs signify attitudes towards objects of a special kind, namely contents; it parts company with lingualism by insisting that in addition to propositional contents consisting of concepts (the contents of human thinking) there are also 'proto-propositional' contents consisting of nonconceptual components, e.g. sensory representations (the contents of animal thinking and pre-reflective human perception). Unfortunately, it is unclear how such proto-propositional entities can be contents of thinking as here understood, i. e. contents signified by the noun-clauses in sentences of the form ' $A V \mathrm{~s}$ (perceives, believes, knows) that $p$ '

Furthermore, this response to the proposition problem in turn leads to a congruity problem. The distinction between different types of content seems to count against ascribing one and the same belief to humans and animals. It suggests that a statement of the form

(25) Both Sarah and the dog believe that $p$

is not so much a falsehood as a syllepsis. For 'Sarah believes that $p$ ' comes out as 'Sarah stands in the relation of believing to the thought that $p$ ' while 'The dog believes that $p$ ' comes out as 'The dog stands in the relation of believing to the protothought that $p$ '.

Such a conclusion would undermine the anti-lingualist motive for introducing the notion of nonconceptual content. At the same time, it seems to support lingualists like Marcus and McDowell. ${ }^{45}$ The latter resists the idea that there is a 'non-conceptual content' common to the perception of humans and animals (though not on account of the

43 Glock (2006).

44 E.g. Cussins (1992); Peacocke (1992); Dummett (1993), chs. 12 f.; Bermúdez (2003).

45 McDowell (1996), 50 f., $63 \mathrm{ff}$. 
congruity problem). Instead, McDowell declares, animals are capable only of 'perceptual sensitivity' rather than genuine experience. In a similar though less dogmatic vein, Malcolm suggests that while the dog can "believe" that the cat went up the oak tree, only humans can "have the thought" that it went up the oak tree. Unfortunately, such a position is faced with an unpalatable dilemma. Either it rejects outright the application of intentional verbs terms like 'perceives', 'thinks' or 'knows' to animals, thereby facing the objections marshaled in section I. Or it diagnoses a fundamental ambiguity in applying such verbs to humans and applying them to animals. In that case, the congruity problem once again raises its ugly head.

Irrespective of whether it arises on account of the content-clause or on account of the intentional verb, the idea that there is such an incongruity is at odds with the way in which ascriptions of beliefs to linguistic and non-linguistic creatures interact. (25) is not a syllepsis like 'Both the exam and the chair were hard'. For it gives rise to perfectly legitimate inferences and explanations. Particularly pertinent is that we can explain a common reaction between Sarah and the dog by reference to statements like (25). If both Sarah and the dog suddenly notice that there is a precipice in front of them, for instance, this explains why both stop dead in their tracks.

We should abandon the unwarranted assumption that an ascription of a belief requires cognitive parity between the ascriber and the subject. A certain disparity between the terms used in a belief report and those that could be used by the subject is present even in the linguistic case, without constituting a fundamental incongruity. The terms which occur in the content-clause are in general dictated not so much "by" the creature whose belief we report, but "by" the concerns of speaker and audience. Thus, 'Sarah thinks that the charlatan you introduced me to is about to give her a biscuit' can be in order, whether Sarah is an adult who regards the person in question as a charlatan, one who does not, a child that lacks the concept of a charlatan, or a dog. ${ }^{46}$

46 See Rundle (1997), 83. 


\section{Doing away with propositional attitudes}

The travails of both differentialism and nonconceptual assimilationism count in favour of a more radical attack on the orthodox, relational account of intentional states epitomized by the idiom of propositional attitudes. Its popularity notwithstanding, the idea that an intentional state is a relation between a subject and a proposition is problematic.

One set of difficulties concerns the building-block model of contents (whether conceptual or nonconceptual). There are both empirical and conceptual qualms about the idea that entertaining a part of a thought correlates with a definite stage of a more protracted mental or neuro-physiological process - the entertaining of the whole thought. Even if these could be waived, we would only be dealing with stages of thinking a thought, not with stages of thoughts. As regards the latter, the building-block model transposes the part/whole relation from the spatial and temporal sphere to a sphere-that of abstract entities - to which $e x$ hypothesis neither spatial nor temporal notions apply. What seems to give sense to talk of parts and wholes in the case of propositions or thoughts is the fact that the linguistic expressions of thoughts-namely sentences-have components—namely words. ${ }^{47}$ What is said or thought can be said to have components only to the extent to which its linguistic expressions have components (these components may, for instance, be what $A$ explains when she is called upon to explain what she means by a particular utterance).

In the wake of Quine, many philosophers regard propositions as dubious entities. They are not just abstract but intensional, and hence, allegedly, lack criteria of identity. Such philosophers often replace propositions by sentences as the objects of propositional attitudes, thereby committing themselves to lingualism. I am more inclined to challenge an assumption which the orthodox view shares with Quinean extensionalists and most proponents of nonconceptual content, namely that intentional verbs signify relations to either abstract or concrete objects. ${ }^{48}$

47 See Kenny (1989), $126 \mathrm{f}$.

48 Davidson's attitude towards the building block model is ambivalent. On the one hand, he denies that having a thought is to stand in a relation to a proposition, on the other, he sees no alternative to treating belief sentences like (1) as relational (Davidson 2001, 37, 57 ff.). Stoecker (Stoecker 2009, 264) ignores the former aspect in maintaining that for Davidson having an intentional attitude is 'standing in a certain relation to a content'. Davidson's measurement analogy, to which Stoecker refers, is designed precisely to avoid this reification. Stoecker 
The idea of propositional attitudes is problematic not just on account of 'propositional' but also on account of 'attitudes'. For the idea that belief is a relation between a subject and an entity amounts to a reification. Admittedly, noun-clauses like 'that the cat went up the oak tree' or 'what Carl believes' are grammatically speaking the objects of beliefs. But they are intentional rather than object-accusatives. ${ }^{49}$

(26) Clare Short believes Tony Blair

entails that there is an object $x$ such that Short believes $x$. In (26) the psychological verb expresses a genuine relation, since here two relata must exist, one to believe, and one to be believed. By contrast,

(27) Short believes that Iraq possesses weapons of mass destruction

does not entail that there is an object $x$ such that Short believes $x$. Nothing in reality need correspond to the noun-phrases of (5) and (27), since the relevant state of affairs need not exist or obtain. ${ }^{50}$

A building-block theorist will dig his heels in and insist that something must exist, namely a (propositional) content which is a real object, though probably an abstract one. But this 'something' is an object only in a formal, grammatical sense; it is a projection from that-clauses rather than a genuine thing to be encountered beyond space and time or in the heads of individuals. ${ }^{51}$ Brentano was right to insist that to believe is to believe something. (27) entails that there is something Short believes. Yet in the first instance this simply means that Short cannot believe any-

thinks that some causal explanations do not refer to causes, and uses this to back up the idea that rational explanations are causal even though actions are not events caused by internal states. But his example of explanations referring to quantitative states is awry. It is wrong to claim that the weight and speed of a truck explain why it broke through the guard vails simply because they narrow down the scope of possible causal processes (as in an inference to the best explanation). Rather, the fact that the truck had a certain impulse (which in turn is a function of weight and velocity) explains the fact that it broke through the barrier.

49 White (1972).

50 This is not the only criterion for an object-accusative, since otherwise factive intentional verbs, as in 'A knows that p'-would govern an object accusative. For more on this point and the following argument see Glock (2010a).

51 Pace Quine, 'something' is wider than 'object'. 'Something' is syntactically transcategorial: it can quantify into the positions of singular term, predicate, and sentence. Only in the first case is it equivalent to 'object'. For the complex relations between these expressions, as well as 'exists', 'there is' and 'real', see Glock (2003), ch. 2. 
thing unless there is an intelligible answer to the question 'What does Short believe?'. If I say 'I believe that $p$ ' and this still leaves you in the dark as to what precisely I believe, I can only respond with an elaboration of what I have said, rather than with a more accurate designation of an object.

Furthermore, the wh-clause 'what Short believes', like 'what Short weighs', incorporates an interrogative rather than a relative pronoun. Thus 'Prescott knows the person Short believes' and 'The person Short believes is Blair' entails 'Prescott knows Blair'. Yet 'Prescott knows what Claire Short believes' and 'What Short believes is that Iraq possesses weapons of mass destruction' does not entail 'Prescott knows that Iraq possesses weapons of mass destruction', if only because one cannot know a falsehood. Similarly, 'Prescott knows what Short weighs' and 'Short weighs $70 \mathrm{~kg}$ ' do not entail 'Prescott knows $70 \mathrm{~kg}$ ', since that sentence is ungrammatical. Neither 'what Short weighs' nor 'what Short believes' signify an object to which Short is related. By the same token, believing that $p$ is no more a genuine relation to an object than weighing $n$ kilograms.

It might be objected that there are pertinent contexts in which 'what Short believes' does incorporate a relative pronoun. In conjunction with (27)

(28) Prescott believes what Short believes

entails

(29) Prescott believes that Iraq possesses weapons of mass destruction.

But the move to (29) is not underwritten by our knowledge that Short and Prescott are related in the same way to an entity. Instead, it is underwritten by the fact that both share certain properties regarding a particular question, namely the question of whether Iraq possesses weapons of mass destruction. Even in this context, 'what Short believes' is an interrogative clause in a less direct sense, since its content derives from the way in which Short would or could respond to a certain question, or react in certain situations, e. g. when voting on the attack on Iraq in Parliament. 


\section{Doing away with propositional attitudes}

The building-block model also goes astray in assuming that the alleged object to which subjects of intentional states are related is a proposition. Many intentional verbs cannot be characterised as expressing a relation either to a proposition or to a sentence. It makes no sense to expect, fear, hope or see a sentence or proposition, at least not the same sense as to expect, fear, hope or see that $p$. And given that what I can expect or see is what you can believe, this difficulty may be contagious. That is to say, it may show that even though it makes sense to believe the proposition that $p$, believing that $p$ is not the same as believing the proposition that $p .^{52}$

One might respond that in its philosophical usage, 'proposition' is a term of art which is exempted from the vagaries of English that rule out locutions like

(30) A fears/expects/hopes/sees the proposition that $p$.

But this invites the challenge to explain what precisely that technical term means. And because of the illicitness of (30) that challenge cannot be met by stipulating that propositions are simply what we believe, expect, hope, etc. ${ }^{53}$

On the other hand, the denial that what we believe is always a proposition seems to imply that in cases in which we do believe the proposition that $p$, we have two beliefs, a belief that $p$ and a belief in the proposition that $p$. And such duplication seems implausible. This objection can be fended off as follows. To say that $A$ believes the proposition that $p$ is not to ascribe to her a belief in addition to her belief that $p$. Rather, it is to place her belief that $p$ in a certain context. Believing that $p$ is simply a matter of believing something to be so, whereas believing the proposition that $p$ is a matter of believing something to be true. In the case of simply believing that $p$, the focus is on how things are or might be; in the case of believing a proposition that $p$ it is on how they have or might be stated or believed to be. The latter construction is appropriate if something has been stated to be so or if such a statement is at least 'in the air', with that statement then being up for consideration regarding its truth.

52 See White (1972); Rundle (2001).

53 See Glock (2011). 


\section{Conclusion}

As regards the basic epistemic and practical notions discussed here, my arguments favour a middle stance between assimilationism and differentialism-cum-lingualism.

On the one hand, the difference between humans and animals does not lie in the fact that the former can and the latter cannot believe, know or act. Nor does it lie in the fact that the latter can believe, know or act only in an attenuated sense. It lies rather in the fact that we can believe, know and do more.

On the other hand, this difference is derivative from our distinctive language-using abilities. Something must count as believing, knowing or desiring that $p$ rather than that $q$, otherwise such ascriptions are vacuous. This means that intentional states, although they need not actually be expressed, must be capable of being expressed. And only a restricted range of intentional states can be expressed in non-linguistic behaviour. $^{54}$

Furthermore, in this case a difference in quantity transforms into a difference in quality - to use a Marxist figure of thought. This holds at two levels. At the factual level, the emergence of language enabled humans to develop techniques and forms of interaction of unprecedented complexity and sophistication. It permitted division of labour and progressive cultural development. And these have set the way humans act, communicate and think-our way of life-fundamentally apart from even the most intelligent and social of animal species. At the conceptual level, the logical connections between epistemic and practical concepts are greatly enhanced when they are applied to linguistic creatures. As a result, in applying our epistemic and practical concepts to animals we employ a rich conceptual apparatus in an area in which some of the logical connections which constitute that apparatus do not apply. But attributing knowledge and action to animals is not simply an impoverished application of a rich technique. For that richer technique evolves around a central core of cases in which creatures believe, know, desire and do things on account of their wants and cognitive capacities. These basics of knowledge and action are shared by humans and animals. ${ }^{55}$

54 See Glock (1997).

55 For comments and suggestions I am grateful to David Dolby, Frank Esken, Tim Henning and participants in the 2010 conference on Human Agency and Human Knowledge at Peking University. I should also like to express my pro- 


\section{References}

Alvarez (2010): Maria Alvarez, Kinds of Reasons, Oxford.

Bekoff/Jamieson (1996): Marc Bekoff/Dale Jamieson (eds.), Readings in Animal Psychology, Cambridge/MA.

Bermudez (2003): José Luis Bermudez, Thinking without Words, Oxford.

Cussins (1992): Adrian Cussins, "Content, embodiment and objectivity", in: Mind 101, 651-688.

Davidson (2001): Donald Davidson, Subjective, Intersubjective, Objective, Oxford.

Dolby (2007): David Dolby, "Propositions, Substitution and Generality", PhD thesis, University of Reading.

Dretske (2004): Fred Dretske, "Seeing, Believing and Knowing", in: R. Schwartz (ed.), Perception, Malden, 268-86.

Dummett (1993): Michael Dummet, Origins of Analytical Philosophy, London.

Ernst (2002): Gerhard Ernst, Das Problem des Wissens, Paderborn.

Fisher (1996): John A. "The Myth of Anthropomorphism", in: Bekoff/Jamieson (1996), 3-16.

Fodor (1975): Jerry Fodor, The Language of Thought, New York.

Gettier (1963): Edmund L. Gettier "Is justified true belief knowledge?", in: Analysis $23,121-3$.

Glock (2000): Hans-Johann Glock, "Animals, thoughts and concepts”, in: Synthese 123, 35-64.

Glock (2001a): Hans-Johann Glock, "Intentionality and Language”, in: Language and Communication 21.2, 105-118.

Glock (2001b): Hans-Johann Glock, "Wittgenstein and Quine: Mind, Language and Behaviour", in:, S. Schroeder (ed.), Wittgenstein and Contemporary Philosophy of Mind, Basingstoke, 3-23.

Glock (2006): Hans-Johann Glock, "Concepts: Representations or Abilities?", in: Content, Consciousness, and Perception, E. Di Nucci/C. McHugh (eds.), Cambridge, 37-61.

Glock (2009): Hans-Johann Glock, "Can Animals Act for Reasons?”, in: Inquiry $52,232-255$.

Glock (2010): Hans-Johann Glock, "Can Animals Judge?”, in: Dialectica 64, $11-34$.

Glock (2010a): Hans-Johann Glock, "Concepts, Abilities and Propositions", in: Grazer Philosophische Studien 81, 115-34.

Glock (2011): Hans-Johann Glock, “A Coquitivist Approach to Concepts”, in: Grazer Philosophische Studien 82, 931-63.

Hurley/Nudds (2006): Susan Hurley/Matthew Nudds(eds.), Rational Animals, Oxford.

Hyman (1999): John Hyman, "How Knowledge Works", in: Philosophical Quarterly 49, 433-51.

Kenny (1963): Anthony J. P. Kenny, Action, Emotion and Will, London.

Kenny (1989): Anthony J. P. Kenny, The Metaphysics of Mind, Oxford.

found gratitude to the organisers of that conference, and to the Hanse-Wissenschaftskolleg Delmenhorst for a research fellowship in 2011. 
McDowell (1996): John McDowell, Mind and World, Cambridge/Mass.

Malcolm (1972-3): Norman Malcolm, "Thoughtless Brutes", in: Proceedings and Addresses of the American Philosophical Society 46.

Marcus (2011): Eric Marcus, Rational Causation, Cambridge/MA.

Peacocke (1992): Christopher Peacocke, A Study of Concepts, Cambridge/MA.

Rundle (1997): Bede Rundle, Mind in Action, Oxford.

Rundle (2001): Bede Rundle, "Objects and Attitudes", in: Language and Communication 21, 143-156.

Ryle (1971): Gilbert Ryle, Collected Papers vol. II, London.

Ryle (1974): Gilbert Ryle, "Mowgli in Babel”, in: Philosophy 49, 5-11.

Ryle (1980): Gilbert Ryle, The Concept of Mind, London.

Seyfarth/Cheney (1996): Robert Seyfarth and Dorothy Cheney, "Inside the Mind of a Monkey", in: Bekoff/Jamieson (1996), 337-343.

Stoecker (2009): Ralf Stoecker, "Why Animals Can't Act", in: Inquiry 52, $255-71$.

Tomasello/Call (1997): Michael Tomasello/Josep Call, Primate Cognition, Oxford.

Tugendhat (1982): Ernst Tugendhat, Traditional and Analytic Philosophy, Cambridge.

Vendler (1972): Zeno Vendler, Res Cogitans, Ithaca.

White (1972): Alan White, "What We Believe", in: N. Rescher (ed.), Studies in the Philosophy of Mind, Oxford, 69-84.

White (1979): Alan White, "Introduction", in: A. White (ed.), The Philosophy of Action, Oxford, 1-18.

White (1982): Alan White, The Nature of Knowledge, Totowa.

Williamson (2000): Timothy Williamson, Knowledge and Its Limits, Oxford.

Wittgenstein (1958): Ludwig Wittgenstein, The Blue and Brown Books, Oxford.

Wittgenstein (1967): Ludwig Wittgenstein, Philosophical Investigations, Oxford. 
Bereitgestellt von | UZH Hauptbibliothek / Zentralbibliothek Zürich 